\section{Deep into the past}

\section{Robert Temple}

Medicine in China. By Paul U. Unschuld with translations and annotations. University of California Press: 1985-1986. Vol. 1 A History of Ideas pp. 423, \$45, £35.95. Vol.2 A History of Pharmaceutics pp.367, $\$ 65$, £51.95. Vol.3 Nan-Ching: The Classic of Difficult Issues pp.760, \$69.95, £55.95.

In this series of books, Paul Unschuld has accomplished monumental labours of translation and annotation. He has a fine historical sense - as for instance when he shows how medicine and politics were inextricably intertwined in second century China during the Yellow Turbans Rebellion - and a colourful and easy style which makes these somewhat esoteric subjects more accessible. But his scholarship, though it can be deep, is not wide. He speaks of his own work as "a completely new approach to Chinese history", which it probably is. It was all the more incumbent on him, therefore, to take more care. In attempting to survey the entire history of Chinese medicine, he has overlooked works on the subject by Fan Hsing-Chun, Sung Ta-Jen, and Wang ChiMin and Wu-Lien Te, as well as important articles by Ch'en Chih, Hu Hou-Hsüan, Yü Yün-Hsiu and R.F. Bridgman. Worse, he cites no work of Joseph Needham more recent than 1980, ignoring several important articles as well as the crucial volume of Science and Civilisation in China on physiological alchemy published in 1983.

On the few occasions when Unschuld mentions Needham, he takes issue with him. For instance, Unschuld insists that acupuncture was not practised in China before the first century $\mathrm{BC}$, whereas Needham gives evidence indicating a date at least four or five centuries earlier. Actually, the hundreds of "hairpins" found in Shang Dynasty tombs may be acupuncture needles, dating the practice to the fourteenth century $\mathrm{BC}$ or earlier. But Unschuld dismisses such possibilities.

The finest of these three volumes is the second, A History of Pharmaceutics, which gives a satisfying survey of Chinese pharmaceutical and herbal writings from the earliest to modern times. Here Unschuld achieves great success, made all the more attractive by the large number of early woodcuts of plants, animals and minerals, reproduced for the first time in the West. Many important texts are translated in this volume, and they are linked together by a coherent and readable commentary. Unschuld is at his best here, with only minor annoyances such as the European translations of Li Shih-chen, China's greatest pharmaceutical writer, being omitted from the bibliography.

Volume 3 is a translation of one of the principal Chinese medical classics, the Nan-Ching, dating from the first century AD. This can only be described as a labour of love, because the work is rather boring to anyone not interested in Chinese medical history. But its availability in a sound philological translation is a great help to scholars, and Unschuld has done a great service which will not go unappreciated. There is no index to the translated text itself, which may be a hindrance for some scholars, especially as the NanChing is enormously long. Unschuld has thoughtfully also provided translation of commentaries on this work by 20 Chinese and Japanese authors over the past 17 centuries. Indeed, his familiarity with Japanese material is a particularly strong

\section{Analytical answers} Nick Walsh

A Handbook of Silicate Rock Analysis. By P. J. Potts. Blackie, Glasgow/Chapman \& Hall, New York:1987. Pp.622. £128, $\$ 175$.

MANY books on silicate analysis have appeared in recent years, but this monumental contribution is different to anything produced so far. It is an attempt to provide a comprehensive account of all the main analytical techniques now in common use for silicate rocks. To undertake this in a multi-author work would be ambitious, but for one author to write such a book is indeed a remarkable achievement. The resulting volume is clear, concise and authoritative, and the discussions of the techniques covered benefit from the uniformity of style. The scope is such that the book should be useful not only to those directly involved in the day-to-day analysis of geological samples but to many other workers as well.

Dr Potts's aim has been to evaluate all of the techniques now used for silicate analysis. Thus the classical (gravimetric) methods are not overlooked, and the "rapid" methods of analysis, developed some 20 years ago (using largely colorimetric/photometric techniques), are presented in adequate detail. Description of modern instrumental methods of elemental analysis takes up most of the book, and there are excellent chapters on atomic absorption, inductively coupled plasma spectrometry and X-ray fluorescence spectrometry (wavelength and energy dispersive). Each of these chapters gives full details of both principles and practice, and with their references they will come to be seen as definitive. The coverage can hardly be faulted, although detailed analytical recipes are not usually given.

A difficulty for any author of a book of this nature is deciding what to include and point, in view of the fact that so much to do with the history of Chinese medicine was lost in China itself and preserved only in Japan.

Future volumes in the series are said to be in preparation, though their specific subjects are not identified. If Unschuld could broaden his range of scholarship and be more careful with citations, his continuing contributions in this field would take on a value proportional to his enormous labours.

Robert Temple, Hill House, Sutton Mallet. Bridgwater, Somerset TA7 9AW, UK, is a historian and science writer. He is author of China: Land of Discovery and Invention (in the United States entitled The Genius of China) recently published by Patrick Stephens/Simon \& Schuster.

what to exclude - it is impossible to accommodate all prejudices. Thus purists may quibble with the appearance of such a detailed treatment of electron probe analysis in a book dealing with rock analysis. This technique is primarily used in the analysis of minerals and its application to rocks is, in the author's word "interesting". Most readers, however, will surely welcome its inclusion, and also that of the short but helpful accounts of "Other Microbeam and Surface Analysis Techniques" (ion probe, laser microprobe, particle-induced X-ray emission, electron spectroscopy for chemical analysis and transmission electron microscopy) that follow. Neutron activation analysis and mass spectrometry (thermal ionization and gas source) are also well represented. Some researchers would probably have preferred to have an even more detailed discussion of isotope dilution methods, in view of their high precision and accuracy. Others may regard the treatment as more than adequate, given the time and cost involved in such analysis. Overall, the balance between description of the techniques themselves, and evaluation of their potential advantages and disadvantages, is the best that could have been attained.

Many other useful topics are included. There are, for example, chapters on ionselective electrodes, ion-exchange separation techniques, gold and platinum group analysis, spark source and inductively coupled plasma mass spectrometry. Of real use to practising analysts are the chapters "Concepts in Analytical Chemistry" and "Optical Spectrometry: Principles and Instrumentation", which provide answers to many fundamental questions.

This is a fine volume, well written and beautifully presented. It is by far the most important book on silicate analysis published in recent years, and given the amount of information included well justifies its apparently hefty price.

Nick Walsh is a Lecturer in the Department of Geology, Royal Holloway and Bedford New College, Egham, Surrey TW20 0EX, UK. 